Brit. Heart f., 1967, 29, 700.

\title{
Hæmodynamic Studies Before and After Electrical Conversion of Atrial Fibrillation and Flutter to Sinus Rhythm
}

\author{
LEON RESNEKOV
}

From the Institute of Cardiology, National Heart Hospital, London W.1

\begin{abstract}
The clinical use of direct current shock in the management of cardiac arrhythmias (Lown, Amarasingham, and Neuman, 1962) has been amply confirmed by many other workers (O'Brien, Resnekov, and McDonald, 1964; Oram et al., 1964; Morris et al., 1964b). The length of time that sinus rhythm persists after the electrical conversion of chronic arrhythmias is often disappointingly short, even when quinidine is prescribed (Resnekov, 1965), and complications following direct current shock are by no means infrequent (McDonald and Resnekov, 1964; Resnekov and McDonald, 1964, 1965). It seemed important therefore to determine what hæmodynamic benefit might be expected following the electrical conversion of atrial fibrillation and flutter to sinus rhythm.
\end{abstract}

\section{SUBJECTS AND Methods}

Fifteen patients were studied (Table I). Atrial fibrillation was present in 12 and atrial flutter in 3 patients. Of the patients with atrial fibrillation, the underlying heart disease was rheumatic mitral or aortic valvar disease in 3, and cardiomyopathy in 2. Chronic ischrmic heart disease was present in 2 and treated thyrotoxicosis in one. In 4 patients, atrial fibrillation was unassociated with clinical evidence of underlying heart disease, and these patients have been labelled as "lone" (Evans and Swann, 1954). No underlying heart disease could be detected in the 3 patients with atrial flutter and these patients were also labelled as "lone". The age range of the 15 patients varied from 31 to 65 years (mean 49.3). There were 12 men and 3 women. The duration of the arrhythmias before conversion, which ranged from 3 weeks to 12 years, and the radiographic size of the heart are given in Table I.

Received October 7, 1966.
Digitalis, when used, was stopped for at least 24 hours before the study. None of the 15 patients was taking quinidine before or after the electrical conversion of the arrhythmia to sinus rhythm. Hæmodynamic studies before and after electrical conversion were made in all the patients according to methods previously described (Resnekov, 1965). In summary, Portex tubing, size FG3, $130 \mathrm{~cm}$. long (external diameter $1.02 \mathrm{~mm}$., internal diameter $0.80 \mathrm{~mm}$.) was passed percutaneously into an arm vein through a no. 18-gauge thin-walled Yale needle, and advanced slowly to the pulmonary artery. Pressure measurements were taken to confirm that the tubing lay in the pulmonary artery. Teflon tubing, TF10 (external diameter $1.0 \mathrm{~mm}$., internal diameter $0.60 \mathrm{~mm}$.), was passed by the technique described by Seldinger (1953) over a nylon guide wire introduced into the brachial artery on the same side as the venous catheter, through a 19-gauge thin-walled Riley needle and advanced for about $30 \mathrm{~cm}$. The patient was asked to sit on a bicycle ergometer (Elema Corporation) with the pulmonary and brachial arterial catheters in position, and pressure recordings were made with reference to the sternal angle using two strain gauges and a multichannel pen recorder. The electrocardiogram (lead CR5) was recorded simultaneously with the pressures from the brachial and pulmonary arteries. Once a steady state had been achieved, expired air was collected for 4 minutes in a Douglas bag, and simultaneous blood samples were obtained from the pulmonary and brachial arteries during the last two minutes. Exercise was then started and performed for six minutes at each of three work loads, or four work loads if the condition of the patient allowed. The approximate physical activity and oxygen uptake at the work loads used is shown in Table II. Pressure measurements and the electrocardiogram were recorded each 30 seconds; during the last two minutes of each work load expired air was collected simultaneously with blood samples from the pulmonary and brachial arteries. Expired air was analysed by a micro-method for oxygen and carbon dioxide con700 
TABLE I

CLINICAL DETAILS, RADIOGRAPHIC SIZE OF HEART, AND DC ENERGY SETTINGS REQUIRED FOR THE ESTABLISHMENT OF SINUS RHYTHM IN 15 PATIENTS

\begin{tabular}{|c|c|c|c|c|c|c|c|}
\hline \multirow{2}{*}{$\begin{array}{c}\text { Patient } \\
\text { No. }\end{array}$} & \multirow{2}{*}{$\begin{array}{c}\text { Age and } \\
\text { sex }\end{array}$} & \multirow[t]{2}{*}{ Underlying heart disease } & \multicolumn{2}{|c|}{ Arrhythmia } & \multicolumn{2}{|c|}{ Radiographic size } & \multirow{2}{*}{$\begin{array}{l}\text { DC energy } \\
\text { setting for } \\
\text { version } \\
\text { (joulest) }\end{array}$} \\
\hline & & & Type & $\underset{(y r .)}{\text { Duration }}$ & $\begin{array}{l}\text { Cardio- } \\
\text { thoracic } \\
\text { ratio }(\%)\end{array}$ & $\begin{array}{c}\text { Left } \\
\text { atrium* } \\
N \text { to }+3\end{array}$ & \\
\hline $\begin{array}{l}1 \\
2 \\
3 \\
4 \\
5 \\
6 \\
7 \\
8 \\
9\end{array}$ & $\begin{array}{l}62 M \\
49 M \\
65 M \\
51 \mathrm{~F} \\
50 M \\
54 M \\
55 M \\
36 M \\
34 \mathrm{~F}\end{array}$ & $\begin{array}{l}\text { Ischæmia } \\
\text { Aortic valve disease post-op. } \\
\text { Ischæmia } \\
\text { Mitral + aortic valve disease } \\
\text { Post thyrotoxicosis } \\
\text { Alc. cardiomyopathy } \\
\text { Lone } \\
\text { Cardiomyopathy } \\
\text { Mitral stenosis post- }\end{array}$ & $\begin{array}{cc}\text { Atrial fibrillation } \\
\text { " } \\
\text { " } \\
\text { " } \\
\text { " } \\
\text { " } \\
\text { " }\end{array}$ & $\begin{array}{l}4 \mathrm{mth} . \\
1 \\
1 \mathrm{mth} . \\
3 \mathrm{mth} . \\
6 \\
1 \\
1 \\
1 \\
12\end{array}$ & $\begin{array}{l}53 \\
49 \\
50 \\
56 \\
50 \\
50 \\
47 \\
52 \\
55\end{array}$ & $\begin{array}{l}+1 \\
+1 \\
+1 \\
+2 \\
N \\
N \\
N \\
+1 \\
+2\end{array}$ & $\begin{array}{r}200 \\
300 \\
100 \\
100 \\
300 \\
300 \\
250 \\
50 \\
200\end{array}$ \\
\hline $\begin{array}{l}10 \\
11 \\
12 \\
13 \\
14 \\
15\end{array}$ & $\begin{array}{l}60 M \\
42 M \\
44 M \\
60 M \\
31 M \\
47 F\end{array}$ & 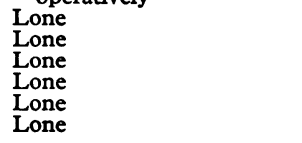 & 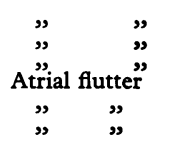 & $\begin{array}{l}3 \mathrm{mth} . \\
9 \mathrm{mth} . \\
5 \\
3 \mathrm{mth} . \\
3 \mathrm{wk} . \\
1\end{array}$ & $\begin{array}{l}50 \\
48 \\
48 \\
48 \\
42 \\
42\end{array}$ & $\begin{array}{l}+1 \\
\mathbf{N} \\
\mathbf{N} \\
\mathbf{N} \\
\mathbf{N}\end{array}$ & $\begin{array}{r}100 \\
300 \\
300 \\
200 \\
50 \\
50\end{array}$ \\
\hline
\end{tabular}

$\mathbf{N}=$ Normal.

$\star$ Size of left atrium graded from a grid film at 40 in. (Resnekov, 1965).

t Delivered using antero-posterior paddles.

venous and arterial blood was determined by the manometric method of Van Slyke and Neill (1924); the cardiac output was calculated (Fick, 1872) and the stroke volume derived. The physical work capacity at a heart rate of 170 beats $/ \mathrm{min}$. ( $\mathrm{PWC}_{170}$ ) was determined by extrapolation of the linear relationship between heart rate and work load.

The day following the hæmodynamic studies phased direct current shock was used to restore sinus rhythm, the energy setting required being shown in Table $I$. The haemodynamic study both at rest and on effort was repeated in an identical fashion 24 or 48 hours after the establishment of sinus rhythm. Stroke volume and heart rate were plotted against the work load before and after the electrical conversion to compare the values during the arrhythmia and in sinus rhythm at equivalent heart rates.

\section{RESULTS}

The mean and standard deviations of the results obtained in the 15 patients studied are shown in Table III. A paired " $t$ " test was obtained for the results during the arrhythmia and in sinus rhythm, at rest and at each work load, and $p$ values are referred to in the text and in Fig. 1-5.

Heart Rate. The heart rate was related in a linear fashion to the work load both during the arrhythmia and in sinus rhythm. The average heart rate at rest during the arrhythmia was 91.4 a minute and varied from 50 to 133 a minute (SD $24 \cdot 8$ ). Following the establishment of sinus rhythm the average heart rate at rest was 79.9 a minute and varied from 63 to 105 a minute (SD 14.2); the difference is statistically significant $(\mathrm{p}<0.001)$. The average heart rate on maximal effort $(600$ $\mathrm{kpm}^{\star} /$ minute) during the arrhythmia in the patients studied was 170.0 a minute and varied from 130 to 200 a minute (SD 22.7). Once sinus rhythm had been established the heart rate at 600 $\mathrm{kpm} /$ minute averaged 139.7 a minute and varied from 110 to 171 a minute (SD 21.2), and the difference is highly significant $(p<0.001)$. The difference between the heart rates during the arrhythmia and in sinus rhythm was exaggerated as the work load increased (Fig. 1).

Physical Work Capacity. The $\mathrm{PWC}_{170}$ averaged $624.2 \mathrm{kpm}$ during the arrhythmia and varied from 200 to $1170 \mathrm{kpm}$ (SD 212.6). In contrast, once sinus rhythm had been established the average $\mathrm{PWC}_{170}$ was $858.9 \mathrm{kpm}$ and varied from 590 to $1050 \mathrm{kpm}$ (SD 153.0), p < 0.001.

Arteriovenous Oxygen Difference. The arteriovenous oxygen difference at rest during the arrhythmia averaged $70.2 \mathrm{ml} . / 1$. and ranged from 56.2 to $97.5 \mathrm{ml} . / 1$. (SD 10.8). Following the establishment of sinus rhythm the average value of the arterio-

TABLE II

WORK LOAD SETTINGS, EQUIVALENT PHYSICAL ACTIVITY, AND APPROXIMATE EXPECTED OXYGEN CONSUMPTION

\begin{tabular}{c|l|c}
\hline $\begin{array}{c}\text { Work load } \\
(\mathrm{kpm} / \mathrm{min} .)\end{array}$ & \multicolumn{1}{|c|}{ Equivalent activity } & $\begin{array}{c}\text { Oxygen uptake } \\
\text { (ml./min.) }\end{array}$ \\
\hline 200 & $\begin{array}{l}\text { Walking at moderate pace } \\
\text { Walking briskly }\end{array}$ & 900 \\
600 & $\begin{array}{l}\text { Running moderately } \\
\text { Running hard }\end{array}$ & 1350 \\
800 & Runn & 2200 \\
\hline
\end{tabular}

$100 \mathrm{kpm}=16$ watts

$\mathrm{kpm} / \mathrm{min} .=$ kilopond-metre per minute 
TABLE III

MEAN HEMODYNAMIC RESULTS IN 15 PATIENTS BEFORE AND AFTER ELECTRICAL CONVERSION OF ATRIAL FIBRILLATION OR FLUTTER TO SINUS RHYTHM

\begin{tabular}{|c|c|c|c|c|c|c|c|c|c|c|c|c|}
\hline \multirow[b]{2}{*}{$\underset{(\mathbf{k p m} / \mathrm{min} .)}{\text { Exercise }}$} & \multicolumn{6}{|c|}{ Before conversion } & \multicolumn{6}{|c|}{ After conversion } \\
\hline & $\begin{array}{l}\text { Heart } \\
\text { rate/ } \\
\text { min. }\end{array}$ & $\begin{array}{c}\text { Oxygen } \\
\text { uptake } \\
\text { (ml./ } \\
\text { min.) }\end{array}$ & $\begin{array}{c}\text { A-V } \\
\text { oxygen } \\
\text { diff. } \\
\text { (ml.) }\end{array}$ & $\begin{array}{l}\text { Cardiac } \\
\text { output } \\
\text { (l./min.) }\end{array}$ & $\begin{array}{c}\text { Stroke } \\
\text { volume } \\
\text { (ml.) }\end{array}$ & $\underset{(\mathrm{kpm})}{\mathrm{PWC}_{170}}$ & $\begin{array}{l}\text { Heart } \\
\text { rate/ } \\
\text { min. }\end{array}$ & \begin{tabular}{|c|} 
Oxygen \\
uptake \\
(mi./ \\
min.)
\end{tabular} & $\begin{array}{c}\text { A-V } \\
\text { oxygen } \\
\text { diff. } \\
\text { (ml.) }\end{array}$ & $\begin{array}{l}\text { Cardiac } \\
\text { output } \\
(1 . / \text { min. })\end{array}$ & $\begin{array}{c}\text { Stroke } \\
\text { volume } \\
(\mathrm{ml} .)\end{array}$ & $\underset{(\mathrm{kpm})}{\mathrm{PWC}}$ \\
\hline $\begin{array}{l}\text { Control } \\
200 \\
400 \\
600\end{array}$ & $\begin{array}{c}91 \cdot 4 \\
(24 \cdot 8) \\
124 \cdot 0 \\
(21 \cdot 8) \\
147 \cdot 0 \\
(21 \cdot 1) \\
170 \cdot 0 \\
(22 \cdot 7)\end{array}$ & \begin{tabular}{|c|}
333.0 \\
$(33.9)$ \\
757.7 \\
$(86.8)$ \\
1151.9 \\
$(123.7)$ \\
1542.7 \\
$(179.7)$
\end{tabular} & $\begin{array}{c}70 \cdot 2 \\
(10 \cdot 8) \\
102 \cdot 8 \\
(9 \cdot 6) \\
118 \cdot 4 \\
(14 \cdot 5) \\
129 \cdot 6 \\
(17 \cdot 3)\end{array}$ & $\begin{array}{c}5 \cdot 2 \\
(0 \cdot 7) \\
7 \cdot 4 \\
(1 \cdot 0) \\
9 \cdot 8 \\
(1 \cdot 5) \\
12 \cdot 1 \\
(2 \cdot 2)\end{array}$ & $\begin{array}{c}60 \cdot 7 \\
(18 \cdot 1) \\
63 \cdot 7 \\
(12 \cdot 4) \\
68 \cdot 1 \\
(13.5) \\
71 \cdot 0 \\
(16 \cdot 4)\end{array}$ & $\begin{array}{c}624 \cdot 2 \\
(212 \cdot 6)\end{array}$ & $\begin{array}{c}79.9 \\
(14 \cdot 2) \\
100 \cdot 2 \\
(13.7) \\
120 \cdot 0 \\
(11 \cdot 3) \\
139 \cdot 7 \\
(21 \cdot 2)\end{array}$ & $\begin{array}{c}356 \cdot 0 \\
(28 \cdot 5) \\
762 \cdot 5 \\
(31 \cdot 5) \\
1177 \cdot 0 \\
(136 \cdot 7) \\
1572 \cdot 0 \\
(204 \cdot 0)\end{array}$ & $\begin{array}{c}68 \cdot 7 \\
(4 \cdot 3) \\
98 \cdot 3 \\
(10 \cdot 1) \\
109 \cdot 3 \\
(7 \cdot 1) \\
113.6 \\
(17.5)\end{array}$ & $\begin{array}{c}5 \cdot 3 \\
(0 \cdot 8) \\
8 \cdot 3 \\
(2 \cdot 1) \\
11 \cdot 4 \\
(1 \cdot 9) \\
14 \cdot 2 \\
(2 \cdot 7)\end{array}$ & $\begin{array}{c}67 \cdot 1 \\
(11 \cdot 1) \\
82 \cdot 2 \\
(13 \cdot 7) \\
94 \cdot 9 \\
(18 \cdot 4) \\
106 \cdot 7 \\
(24 \cdot 4)\end{array}$ & $\begin{array}{c}858 \cdot 9 \\
(153 \cdot 0)\end{array}$ \\
\hline
\end{tabular}

* Expressed as STPD.

$+\mathrm{PW} \mathrm{C}_{170}=$ Physical work capacity at heart rate of $170 / \mathrm{min}$. (See text.) Standard deviations are in parentheses.

venous oxygen difference at rest was reduced to $68.7 \mathrm{ml} . / 1$. (range 55.0 to $96 \cdot 5$, SD 4.3 ), but the difference is not statistically significant, $\mathrm{p}<0.05$. The mean arteriovenous oxygen difference at 200 $\mathrm{kpm} /$ minute was $102.8 \mathrm{ml}$./l. (range 88.5 to $116 \cdot 2$, SD 9.6) during the arrhythmia and $98.3 \mathrm{ml} . / 1$. (range 66.6 to $110 \cdot 8, \mathrm{SD} 10 \cdot 1$ ) in sinus rhythm, and is statistically significant $(p<0.001)$. At $400 \mathrm{kpm} /$ minute, the corresponding figures were $118.4 \mathrm{ml} . / 1$. (range 98.8 to 140.8, SD 14.5 ) during the arrhythmia and $109 \cdot 3 \mathrm{ml} . / 1$. (range $72 \cdot 7$ to $123 \cdot 2$, SD $7 \cdot 1$ ) in sinus rhythm $(\mathrm{p}<0.001)$. At $600 \mathrm{kpm}$ the mean value was $129.6 \mathrm{ml} . / 1$. (range 104.2 to $170 \cdot 1$, SD $17 \cdot 3$ ) during the arrhythmia and $113.6 \mathrm{ml} / 1$. (range 74.5 to $138 \cdot 5$, SD $17 \cdot 5)$ in sinus rhythm $(\mathrm{p}<0.001)$

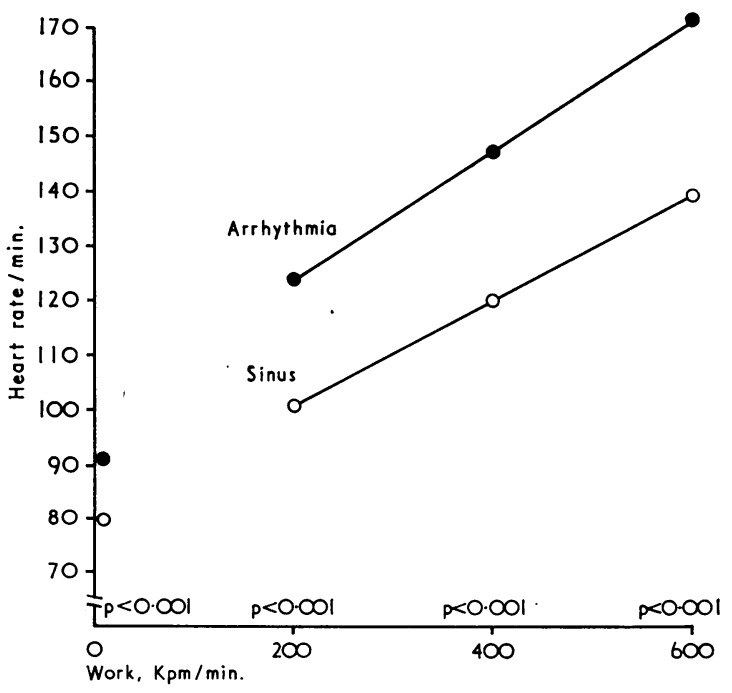

Fig. 1.-Mean of the heart rates of 15 patients at rest and exercising at increasing work loads during arrhythmia and in sinus rhythm.
(Fig. 2). The reduction in the arteriovenous oxygen difference was due to the higher oxygen content of mixed venous blood at rest and on effort in sinus rhythm, and desaturation of arterial blood did not occur during exercise in any of the patients studied.

Oxygen Uptake. The investigations were performed under strictly comparable conditions during the arrhythmia and in sinus rhythm, and great care was taken to ensure that all the expired air was collected in the Douglas bag. The difference in the volume of oxygen uptake at rest and on effort measured during the arrhythmia and in sinus rhythm was not statistically significant at rest or on effort (Fig. 3).

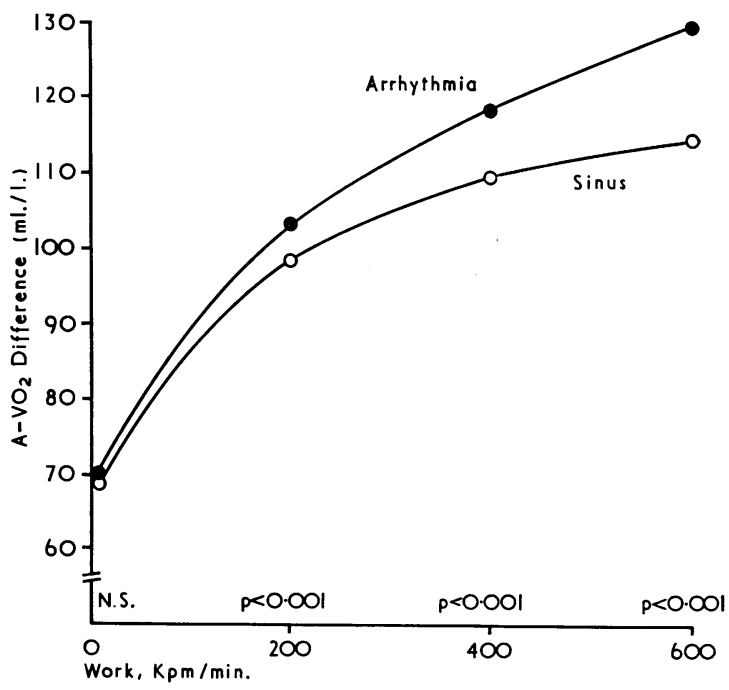

FIG. 2.-Mean arteriovenous oxygen difference in 15 patients at rest and on exercise plotted against work load. N.S.= difference not significant. 
Cardiac Output. The mean cardiac output at rest during the arrhythmia was $5 \cdot 2 \mathrm{l} . / \mathrm{min}$. (range 3.3 to 6.3 , SD 0.73) and following the establishment of sinus rhythm $5.31 . / \mathrm{min}$. (range 3.3 to $7 \cdot 7$, SD $0 \cdot 89$ ). The difference is not statistically significant $(t=0.29, p<0.05)$. A significant difference occurred, however, with the stress of exercise, and was accentuated as the work load increased. The mean cardiac output measured at $200 \mathrm{kpm} / \mathrm{min}$. was $7 \cdot 4 \mathrm{l} . / \mathrm{min}$. (range 4.5 to $8 \cdot 7$, SD 1.01 ) during the arrhythmia and $8.31 . / \mathrm{min}$. (range 4.7 to 10.7 , SD 2.05) in sinus rhythm, a difference of 0.9 $1 . / \mathrm{min} ., \mathrm{p}<0.001$. Comparable values at $600 \mathrm{kpm} /$ $\mathrm{min}$., however, were $12.11 \mathrm{l} / \mathrm{min}$. (range 8.0 to 15.2 , SD $2 \cdot 2$ ) during the arrhythmia and $14.21 . / \mathrm{min}$. (range $9 \cdot 1$ to $17 \cdot 3$, SD $2 \cdot 7$ ), a difference of $2 \cdot 1$ $1 . / \mathrm{min}$. $(\mathrm{p}<0.001)$. These changes are shown graphically in Fig. 4.

Stroke Volume. The stroke volume averaged $60.7 \mathrm{ml}$. (range 37 to $104, \mathrm{SD} 18 \cdot 1$ ) at rest during the arrhythmia and was significantly higher during sinus rhythm, being $68.7 \mathrm{ml}$. (range 48 to $79, \mathrm{SD}$ $11 \cdot 1, \mathrm{p}<0.01)$. This difference increased with the stress of exercise. The stroke volume at 200 $\mathrm{kpm} / \mathrm{min}$. during the arrhythmia was $63.7 \mathrm{ml}$. (range 44 to $87, \mathrm{SD} 12.4$ ) and $82.2 \mathrm{ml}$. (range 55 to $107, S D$ 13.7) in sinus rhythm, a difference of $18.5 \mathrm{ml}$. $(\mathrm{p}<0.001)$ : comparable figures at $600 \mathrm{kpm} / \mathrm{min}$. were $71.0 \mathrm{ml}$. (range 54 to 104 , SD 164) during the arrhythmia, and $106.7 \mathrm{ml}$. (range 66 to 139, SD

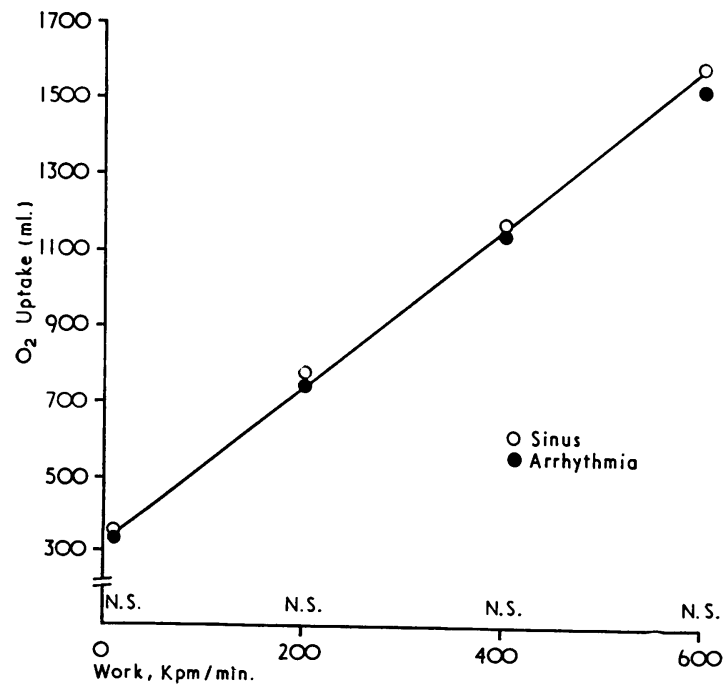

FIG. 3.-Mean oxygen uptake in 15 patients at rest and on exercise plotted against work load. N.S.= difference not significant
$24 \cdot 4$ ) in sinus rhythm, a difference of $35.7 \mathrm{ml}$. $(p<0.001)$ (see Fig. 5). The mean of the stroke volumes at increasing heart rates is shown in Fig. 6. During the arrhythmia there is little change in stroke volume with increasing heart rates, but in sinus rhythm the stroke volume rises up to a heart rate of 130-140 per minute whereafter it remains constant.

Pressure Measurements. There was no consistent change between the mean of the pulmonary and brachial arterial pressures at rest and on exercise during the arrhythmia and in sinus rhythm measured with reference to the sternal angle. Typical pressure tracings are shown in Fig. 7. Systolic pulmonary arterial pressure rose from normal values to $40 \mathrm{~mm}$. Hg or more, on the highest exercise loads in four patients. Two patients developed marked systolic and diastolic systemic hypertension during exercise but neither had evidence of hypertension in the past.

\section{Discussion}

These results show that there is a significant increase in the cardiac output in sinus rhythm as compared with measurements made during atrial fibrillation or flutter. The difference was not always present at rest, but could invariably be provoked by exercise, and was accentuated as the exercise level was increased. The findings differ from those of Graettinger, Carleton, and Muenster (1964) on supine exercise but are in agreement as regards the

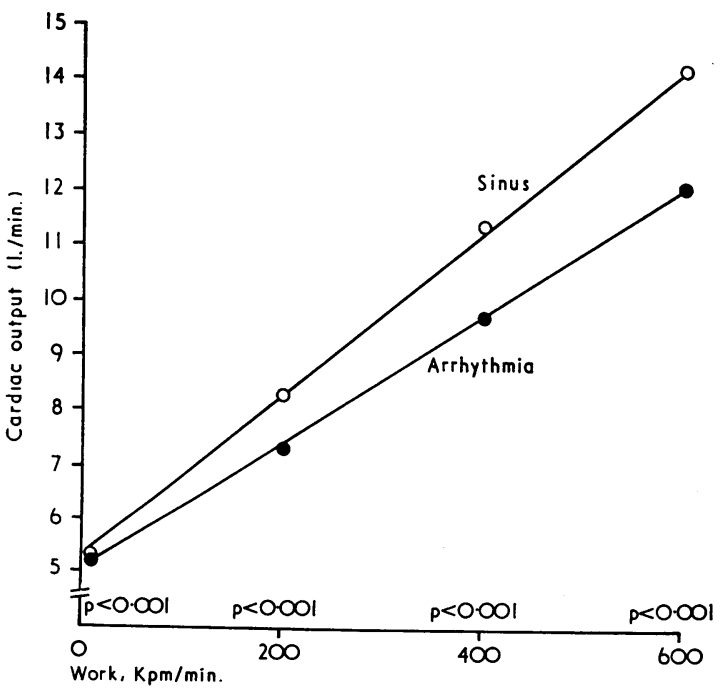

FIG. 4.-Mean cardiac output in 15 patients at rest and on exercise plotted against work load. 


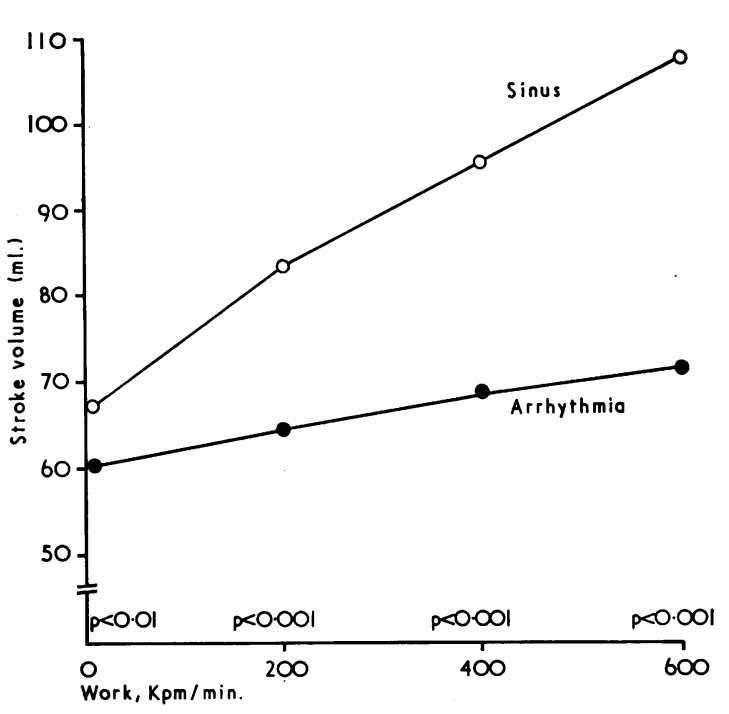

FIG. 5.-Mean stroke volume in 15 patients at rest and on exercise plotted against work load.

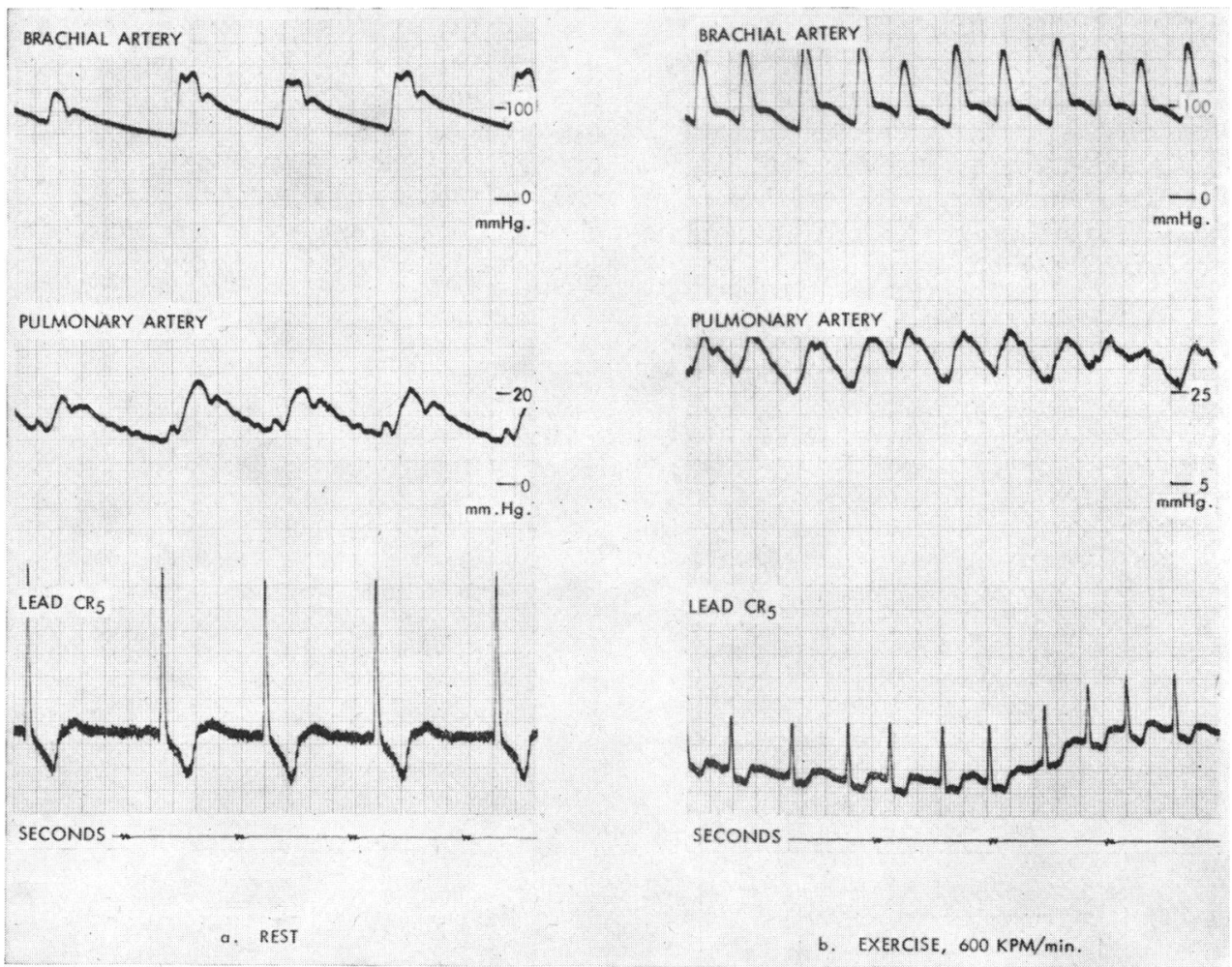

FIG. 7.-Pressures recorded simultaneously from the pulmonary and brachial arteries and lead $\mathrm{CR}_{5}$ during atrial fibrillation.

(a) At rest, sitting on the bicycle.

(b) During the sixth minute of exercise at $600 \mathrm{kpm} / \mathrm{min}$. Note: the sensitivity of the cardiogram has been reduced during exercise to lessen the effect of respiratory 
cardiac output at rest in atrial fibrillation and sinus rhythm. The levels of oxygen consumption on effort, however, are considerably less in the investigations done by these authors and rarely exceeded $300 \mathrm{ml} . / \mathrm{min} . / \mathrm{m}^{2}$ body surface area, whereas oxygen consumption during the maximum exercise load in the present series was usually three times higher. It may well be, therefore, that more severe exercise in their investigation would have demonstrated an increased cardiac output in sinus rhythm.

The series reported by Oram et al. (1963) was unusual in that a mean increase of 70 per cent in the cardiac output measured at rest was found in patients studied in sinus rhythm up to 16 days after electrical conversion. The preconversion levels of the cardiac output were excessively low in some of these patients, however. Large increases in cardiac output following the establishment of sinus rhythm are also reported by Halmos and Patterson (1965) and by Kahn et al. (1964). Benchimol, Lowe, and Akre (1965) who studied eight patients before and after the conversion of atrial fibrillation to sinus rhythm also demonstrated that the improvement in cardiac function when in sinus rhythm was more evident during exercise. Morris et al. (1964a) showed an average increase in cardiac output at rest of 34 per cent in 7 of 11 patients converted to sinus rhythm, while all five patients studied on exercise had an average increase in cardiac output of 17 per cent.

Three patients with atrial fibrillation had no detectable underlying heart disease responsible for the arrhythmia. All three patients showed hæmodynamic improvement in sinus rhythm (Table IV). Indeed, in one patient an extra work load of 200 $\mathrm{kpm} / \mathrm{min}$. to a total of $800 \mathrm{kpm} / \mathrm{min}$. was possible in sinus rhythm, and was achieved with a heart rate in sinus rhythm similar to the heart rate at 600 $\mathrm{kpm} / \mathrm{min}$. during the arrhythmia. Similar beneficial results in sinus rhythm were found when the cardiac output and therefore the stroke volume measurements were compared. In contrast, Baer,
Weglarz, and Killip (1964) and Killip and Baer (1966) found no improvement after sinus rhythm had been achieved in the lone fibrillation group.

There was a most satisfactory improvement in the circulation following the establishment of sinus rhythm in patient No. 2 whose aortic valve had been replaced six weeks before study. In atrial fibrillation, the increase in cardiac output on exercise was entirely rate dependent, and the stroke volume fell progressively as the exercise load increased (Fig. 8); once sinus rhythm had been achieved, however, a more normal response to exercise occurred, and the stroke volume was maintained even at a heart rate of 150 beats a minute.

The occurrence of hæmodynamic benefit in sinus rhythm on exercise, was not dependent on the nature of the underlying heart disease in the 15 patients, in this series, which is in agreement with the findings of McIntosh, Kong, and Morris (1964) and of McIntosh and Morris (1966) who reviewed the subject. Efficient atrial systole, however, is particularly important in conditions associated with valvar or subvalvar obstruction of the left ventricle and in diseases causing a diminished compliance of that chamber (Braunwald and Frahm, 1961). The patients who had a virtually normal heart once sinus rhythm had been achieved benefited more than those with underlying heart disease.

The increase in the cardiac output in sinus rhythm resulted in a decrease in the arteriovenous oxygen difference since oxygen consumption during the arrhythmia and in sinus rhythm was not significantly altered, as was also found by Morris et al. (1963) and Graettinger et al. (1964).

Body posture has a profound effect on the circulation both at rest and on exercise (Bevegård, Holmgren, and Jonsson, 1960). Cardiac output and stroke volume are both less in the sitting position than in the supine. These changes occur at rest (McMichael and Sharpey-Schafer, 1944; Donald et al., 1953) and are probably due to a redistribution

TABLE IV

HEART RATE AND CARDIAC OUTPUT IN 3 PATIENTS WITH LONE ATRIAL FIBRILLATION BEFORE AND AFTER CONVERSION TO SINUS RHYTHM AT REST AND ON EFFORT

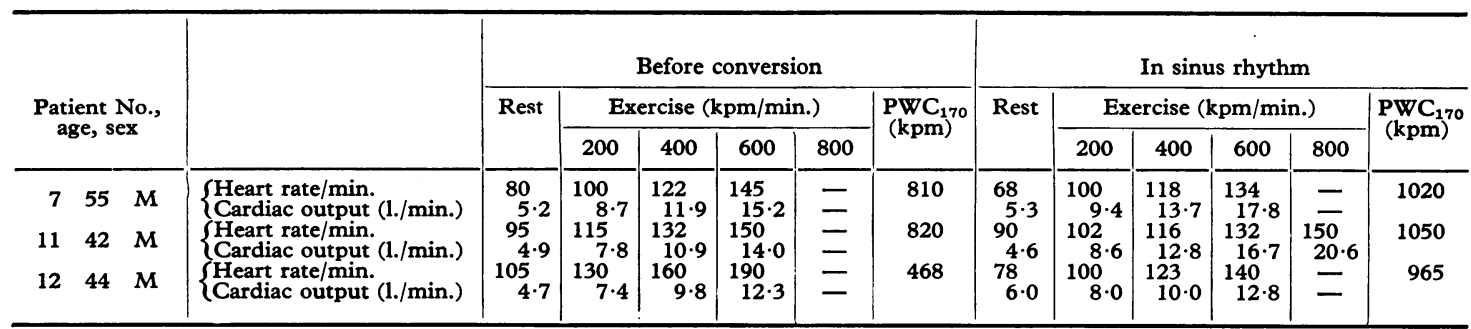

$\mathrm{PWC}_{170}=$ Physical work capacity at a heart rate of $170 / \mathrm{min}$. 


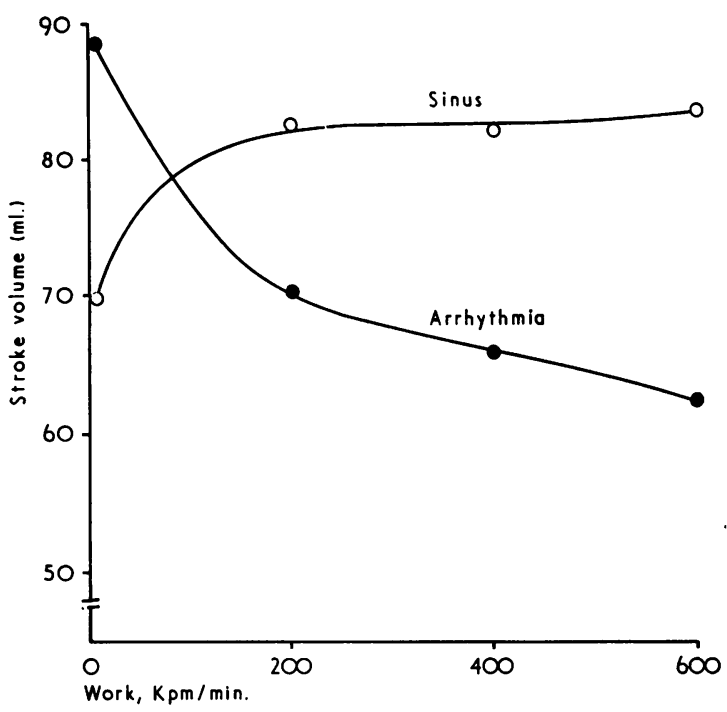

Fig. 8.-Stroke volume plotted against work load in Patient No. 2 studied in atrial fibrillation and in sinus rhythm six weeks after aortic valve replacement. Note the progressive fall in stroke volume with exercise during the arrhythmia.

of blood from the thorax to the legs. The effect of position on the circulation is therefore important and could be responsible for some of the conflicting reports on hæmodynamic changes before and after the conversion of arrhythmias to sinus rhythm. All measurements in this study whether at rest or on effort were made sitting on the bicycle ergometer.

The concept of the physical work capacity as a measure of the work performed per heart beat was put forward by Sjöstrand (1947) and by Wahlund (1948). The physical work performed by a patient pedalling a bicycle ergometer at a heart rate of $\mathbf{1 7 0}$ per minute was obtained in the present investigation from the linear relation between heart rate and work performed. The $P W C_{170}$ is reduced in the presence of heart disease (Holmgren et al., 1957), but in addition the present investigation has shown that the combined effects of the loss of atrial systole and a more rapid ventricular rate on exercise during the arrhythmia significantly lowers the work capacity.

There have been several reports on the changes in cardiac output before and after the conversion by quinidine of atrial fibrillation to sinus rhythm. The results are often conflicting. Storstein and Tveten (1955) found an increase in cardiac output when in sinus rhythm but attributed this in part to the effect of quinidine on the peripheral circulation and on the myocardium; this concept was later challenged by Broch and Müller (1957) who found no evidence that quinidine was beneficial in the way suggested. Kory and Meneely (1951) failed to demonstrate an improvement in the cardiac output in sinus rhythm, but Hansen, McClendon, and Kinsman (1952) succeeded in doing so.

Numerous investigators have paid attention to the circulatory function of the atrium. Harvey (1628) described the action of the atrium as an act of contraction, throwing blood into the ventricle. Henderson (1906), however, concluded that in dogs the atrium was more important as an elastic reservoir, and recently Grant, Bunnell, and Greene (1964) concluded the same of man. Lewis (1912) showed that at a given rapid ventricular rate a regular or irregular ventricular contraction would lead to the same decrease in blood pressure, and he thought that the changes in the circulation recorded during atrial fibrillation were entirely rate dependent. Gesell (1911), however, had already shown that an appropriately timed atrial systole would augment blood pressure, and later (Gesell, 1916) was able to show that the immediate effect of atrial systole was to amplify the cardiac output by 30 per cent. Ventricular plethysmography was used by Straub (1910), Hirschfelder (1908), and Wiggers and Katz (1922) who concluded that ventricular filling was augmented by atrial systole and that this contribution no longer occurred in atrial fibrillation. Stewart, Crawford, and Hastings (1926) demonstrated that the cardiac output in dogs decreased by as much as 60 per cent during atrial fibrillation. It was suggested by Stewart, Crawford, and Gilchrist (1928) that this resulted from a decrease in the oxygen saturation of mixed venous blood. A disproportionate increase in the ventricular rate on exercise is found in patients with atrial fibrillation, as shown by Blumgart (1924). This is confirmed in the present series which shows, moreover, that even when digitalized to therapeutic levels the rate response to the stress of exercise is excessive in atrial fibrillation; some rate benefit does occur in the digitalized heart, however, as suggested by Modell, Gold, and Rothendler (1941).

It could be argued that the circulatory benefit in sinus rhythm is entirely rate dependent. Knox (1949) and Wetherbee, Brown, and Holzman (1952) agreed with earlier workers, that the major disability of atrial fibrillation was the rapid ventricular rate, especially on exercise. With the establishment of sinus rhythm and consequent slowing of the heart an increased diastolic filling time would result in a larger stroke volume and cardiac output. Stroke volumes were larger in sinus rhythm than in atrial fibrillation and atrial flutter at equivalent heart rates (Fig. 6), and increased more in sinus rhythm as the heart rate rose to 120 a minute. With a further 
increase in heart rate, the stroke volume remained constant in sinus rhythm but began to fall during the arrhythmia. These figures are deduced from studies in which it is known that the oxygen uptake is similar and the work load is identical; as the heart rate is also similar the beneficial results in sinus rhythm cannot be explained only on the basis of an increased diastolic filling time, but must also be due to the benefit of atrial systole in sinus rhythm. This is in agreement with the conclusions of Skinner et al. (1964) who demonstrated that a fall in stroke volume and cardiac output occurred in anæsthetized dogs, with the onset of atrial fibrillation even when the ventricular rate remained constant.

The results in this series suggest that when the heart is healthy, the atrium functions as a "booster pump" to improve ventricular filling on exercise; when the heart is abnormal, however, the atrial contribution to ventricular filling is important even at rest, as shown by Braunwald and Frahm (1961). There is little confirmatory evidence in man that an efficient atrial systole prevents atrio-ventricular regurgitation, as suggested by Little (1951) and by Sarnoff, Gilmore, and Mitchell (1962), and Braunwald et al. (1966) failed to demonstrate mitral regurgitation on cine-angiography in patients lacking atrial systole.

\section{SUMMARY}

The hæmodynamic changes in 15 patients were studied at rest and during graded exertion before and after the electrical conversion of atrial fibrillation or flutter to sinus rhythm. There was no significant change at rest when the heart was normal apart from the arrhythmia, but atrial systole appeared important even at rest when the ventricle was diseased. On exercise, the beneficial effects of sinus rhythm were demonstrated with normal and abnormal hearts and the larger the exercise load the greater the benefit. A disproportionate increase in heart rate occurred when patients were exercised during atrial fibrillation and flutter even when digitalized, and the physical work capacity was reduced. The cardiac output and stroke volume were less for equivalent work loads during the arrhythmia. Equivalent exercise loads were performed in sinus rhythm at a slower heart rate, the physical work capacity was higher, and cardiac output and stroke volume were increased, resulting in a narrower arteriovenous oxygen difference. A paired " $t$ " test demonstrated that the changes were highly significant. The stroke volumes were compared during the arrhythmia and in sinus rhythm at equivalent heart rates at rest and on exercise; in sinus rhythm, the stroke volume was larger and was held more constant as the heart rate increased under the stress of exercise. The hæmodynamic benefit of atrial systole actively filling the ventricle during exercise or in the presence of a diseased ventricle was deduced.

I wish to thank the physicians and surgeons of the National Heart Hospital for allowing me to investigate patients under their care.

\section{REFERENCES}

Baer, R., Weglarz, S., and Killip, T. (1964). Cardiac function in atrial fibrillation and sinus rhythm. (Abstract.) Clin. Res., 12, 175.

Benchimol, A., Lowe, H. M., and Akre, P. R. (1965). Cardiovascular response to exercise during atrial fibrillation and after conversion to sinus rhythm. Amer.F.Cardiol., 16,31 .

Bevegård, S., Holmgren, A., and Jonsson, B. (1960). The effect of body position on the circulation at rest and during exercise, with special reference to the influence on the stroke volume. Acta physiol. scand., 49, 279.

Blumgart, H. (1924). The reaction to exercise of the heart affected by auricular fibrillation. Heart, 11, 49.

Braunwald, E., and Frahm, C. J. (1961). Studies on Starling's law of the heart. IV. Observations on the hemodynamic functions of the left atrium in man. Circulation, 24, 633.

—, Rockoff, S. D., Oldham, H. N., Jr., and Ross, J., Jr. (1966). Effective closure of the mitral valve without atrial systole. Circulation, 33, 404.

Broch, O. J., and Müller, O. (1957). Hæmodynamic studies during auricular fibrillation and after restoration of sinus rhythm. Brit. Heart f., 19, 222.

Donald, K. W., Bishop, J. M., Cumming, G., and Wade, O. L. (1953). The effect of nursing positions on the cardiac output in man. Clin. Sci., 12, 199.

Evans, W., and Swann, P. (1954). Lone auricular fibrillation. Brit. Heart F., 16, 189.

Fick, A. (1872). Ueber die Messung des Blutquantums in den Herzventrikeln. xiv. Sitzung am 9 Juli 1870. In Verh. phys-med. Ges. Würzb., n.s. 2, Sitzungsberiche phys.-med. Ges. 1870, p. xvi.

Gesell, R. A. (1911). Auricular systole and its relation to ventricular output. Amer.F. Physiol., 29, 32.

- (1916). Cardiodynamics in heart block as affected by auricular systole, auricular fibrillation and stimulation of the vagus nerve. Amer. F. Physiol., 40, 267.

Graettinger, J. S., Carleton, R. A., and Muenster, J. J. (1964). Circulatory consequences of changes in cardiac rhythm produced in patients by transthoracic direct-current shock. F. clin. Invest., 43, 2290.

Grant, C., Bunnell, I. L., and Greene, D. G. (1964). The reservoir function of the left atrium during ventricular systole. An angiographic study of atrial stroke volume and work. Amer. F. Med., 37, 36.

Halmos, P. B., and Patterson, G. C. (1965). Effect of atrial fibrillation on cardiac output. Brit. Heart f., 27, 719.

Hansen, W. R., McClendon, R. L., and Kinsman, J. M. (1952). Auricular fibrillation: hemodynamic studies before and after conversion with quinidine. Amer. Heart F., 44, 499.

Harvey, W. (1628). De Motu Cordis. Keynes Edition, 1928.

Henderson, Y. (1906). The volume curve of the ventricles of the mammalian heart, and the significance of this curve in respect to the mechanics of the heart-beat and the filling of the ventricles. Amer. F. Physiol., 16, 325. 
Hirschfelder, A. D. (1908). The volume curve of the ventricles in experimental mitral stenosis, and its relation to physical signs. Bull. Fohns Hopk. Hosp., 19, 319.

Holmgren, A., Jonsson, B., Levander, M., Linderholm, H., Sjöstrand, T., and Ström, G. (1957). Low physical working capacity in suspected heart cases due to inadequate adjustment of peripheral blood flow (vasoregulatory asthenia). Acta med. scand., 158, 413.

Kahn, D. R., Wilson, W. S., Weber, W., and Sloan, H. (1964). Hemodynamic studies before and after cardioversion. f. thorac. cardiovasc. Surg., 48, 898.

Killip, T., and Baer, R. A. (1966). Hæmodynamic effects after reversion from atrial fibrillation to sinus rhythm by precordial shock. F. clin. Invest., 45, 658.

Knox, J. A. C. (1949). The heart rate with exercise in patients with auricular fibrillation. Brit. Heart f., 11, 119.

Kory, R. C., and Meneely, G. R. (1951). Cardiac output in auricular fibrillation with observations on the effects of conversion to normal sinus rhythm. F. clin. Invest., 30, 653.

Lewis, T. (1912). Fibrillation of the auricles: its effects upon the circulation. F. exp. Med., 16, 395.

Little, R. C. (1951). Effect of atrial systole on ventricular pressure and closure of the $\mathrm{A}-\mathrm{V}$ valves. Amer. $\mathcal{F}$. Physiol., 166, 289.

Lown, B., Amarasingham, R., and Neuman, J. (1962). New method for terminating cardiac arrhythmias. Use of synchronized capacitor discharge. f. Amer. med. Ass., $182,548$.

McDonald, E. L., and Resnekov, L. (1964). Atrial defibrillation. In Resuscitation and Cardiac Pacing, ed. G. Shaw, G. Smith, and T. J. Thomson, p. 140. Cassell, London.

McIntosh, H. D., Kong, Y., and Morris, J. J., Jr. (1964). Hemodynamic effects of supraventricular arrhythmias. Amer. F. Med., 37, 712.

- , and Morris, J. J., Jr. (1966). The hemodynamic consequences of arrhythmias. Progr. cardiovasc. Dis., 8, 330.

McMichael, J., and Sharpey-Schafer, E. P. (1944). Cardiac output in man by a direct Fick method. Effects of posture, venous pressure change, atropine, and adrenaline. Brit. Heart $\mathcal{F}$., 6, 33.

Modell, W., Gold, H., and Rothendler, H. H. (1941). Use of digitalis to prevent exaggerated acceleration of the heart during physical exercise in patients with auricular fibrillation. f. Amer. med. Ass., 116, 2241.

Morris, J. J., Jr., Entman, M. L., North, W. C., Kong, Y., and McIntosh, H. D. (1964a). The changes in cardiac output with reversion of atrial fibrillation to sinus rhythm. Circulation, 31, 670.

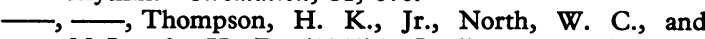
McIntosh, H. D. (1963). Cardiac output in atrial fibrillation and in sinus rhythm. (Abstract.) Circulation, 28, 772 .

—, Kong, Y., North, W. C., and McIntosh, H. D. (1964b). Experience with "cardioversion" of atrial fibrillation and flutter. Amer. F. Cardiol., 14, 94.

O'Brien, K., Resnekov, L., and McDonald, L. (1964). Direct-current countershock in the treatment of drugresistant arrhythmias. Brit. Heart f., 26, 137.
Oram, S., Davies, J. P. H., Weinbren, I., and Taggart, P. (1964). Conversion of atrial fibrillation to sinus rhythm by direct-current shock. Brit. Heart f., 26, 137.

$\longrightarrow,-,-$, , and Kitchen, L. D. (1963). Conversion of atrial fibrillation to sinus rhythm by directcurrent shock. Lancet, 2, 159.

Resnekov, L. (1965). Synchronised capacitor discharge in the management of cardiac arrhythmias with particular reference to the hæmodynamic significance of atrial systole. M.D. Thesis, University of Cape Town.

- , and McDonald, L. (1964). Contraindications and reasons for failure in the treatment of arrhythmias by direct-current countershock. Abstracta IV Congressus Cardiologicus Europæus Pragæ, p. 275.

- and - (1965). Pulmonary cedema following treatment of arrhythmias by direct-current shock. Lancet, $1,506$.

Sarnoff, S. J., Gilmore, J. P., and Mitchell, J. H. (1962). Influence of atrial contraction and relaxation on closure of mitral valve. Circulat. Res., 11, 26.

Scholander, P. F. (1947). Analyzer for accurate estimation of respiratory gases in one-half cubic centimeter samples. F. biol. Chem., 167, 235.

Seldinger, S. I. (1953). Catheter replacement of the needle in percutaneous arteriography. A new technique. Acta radiol. (Stockh.), 39, 368.

Sjöstrand, T. (1947). Changes in the respiratory organs of workmen at an ore smelting works. Acta med. scand., 196, Suppl., p. 687.

Skinner, N. S., Jr., Mitchell, J. H., Wallace, A. G., and Sarnoff, S. J. (1964). Hemodynamic consequences of atrial fibrillation at constant ventricular rates. Amer. $\mathcal{F}$. Med., 36, 342.

Stewart, H. J., Crawford, J. H., and Gilchrist, A. R. (1928). Studies on the effect of cardiac irregularity on the circulation. I. The relation of pulse deficit to rate of blood flow in dogs subject to artificial auricular fibrillation and to regular tachycardia. $\mathcal{F}$. clin. Invest., $5,317$.

$\longrightarrow,-$, and Hastings, A. B. (1926). The effect of tachycardia on the blood flow in dogs. I. The effect of rapid irregular rhythms as seen in auricular fibrillation. F. clin. Invest., 3, 435.

Storstein, O., and Tveten, H. (1955). The hemodynamic effect of restoring normal sinus rhythm in patients with auricular fibrillation. Scand. F. clin. Lab. Invest., 7, 167.

Straub, H. (1910). The diastolic filling of the mammalian heart. F. Physiol. (Lond.), 40, 378.

Van Slyke, D. D., and Neill, J. M. (1924). The determination of gases in blood and other solutions by vacuum extraction and manometric measurement. $\mathcal{F}$. biol. Chem., 61, 523.

Wahlund, H. (1948). Determination of the physical working capacity. Acta med. scand., Suppl. 215.

Wetherbee, D. G., Brown, M. G., and Holzman, D. (1952). Ventricular rate response following exercise during auricular fibrillation and after conversion to normal sinus rhythm. Amer. F. med. Sci., 223, 667.

Wiggers, C. J., and Katz, L. N. (1922). The contour of the ventricular volume curves under different conditions. Amer. F. Physiol., 58, 439. 